\title{
Performing nature unnaturally: Musique concrète and the performance of knowledge - one seabird at a time.
}

\author{
Keywords \\ Anthropocene, Musique concrète, Seabirds, Multimedia art, Sustainability.
}

Migratory seabirds are an unseen conduit between marine and terrestrial systems, carrying the nutrients they consume at sea into the forests where they breed. Acting as environmental sentinels, their health and reproductive success provide early warning signals of deteriorating marine eco-systems as the climate changes, and fish stocks decrease. Aotearoa New Zealand is the seabird capital of the world, with $\sim 25 \%$ of all species breeding here and $\sim 10 \%$ exclusively so. They play a critical role in maintaining healthy ecosystems, with their long-term well-being is closely interconnected with our own prospects for a sustainable future. Now predominantly restricted to off-shore islands due to predation and habitat destruction, seabirds and their familiar sounds have become less available in an age when the unprecedented global movement and planetary spread of the human population has culminated in unsustainable fishing, predators and habitat destruction. Inspiring mythology, song, poetry and stories, birds have been significant in shaping our understanding of how our natural environment has come to be known and understood. This paper speculates upon how we learn to communicate and cooperate with these precious taonga, and what might be learned from such an exchange through creative practice. Reflecting upon what birds might tell us, musician Matthew Bannister and I, a visual artist, have taken our cue from seabirds sharing our local environment on the west coast of Aotearoa - from the petrel (peera) through to the gannet (tākapu). Working on the premise that bird vocalisation is a performed negotiation that includes defence of territory and mate attraction, a bird's call is a form of communication that effectively says "Come here" or "Go away", which arguably is true of music - marking a social space and time to invite or repel. Rather than limiting bird calls to functionalist categories of explanation, we ask whether seabirds can communicate and exchange information about environmental changes using a malleable vocabulary, comprised of unique acoustic units arranged and re-arranged sequentially for greater communicative depth. Granting a high level of agency and creativity to birds as opposed to believing a bird only avails itself of stereotyped 'speech' to survive an accident-rich environment, places greater importance on responses that are improvised directly upon environmental stimuli as irritant rather than as a signal. Matthew explores bird calls via musique concrète, sampling recordings of seabirds to abstract the musical values of bird song conventions - a human response to the 'other' in jointly formed compositions, reflecting a living evolving relationship between composer and bird. In further developing our research into a multimedia artwork, I shall extend a technique used for electroacoustic composition (granular synthesis) to video portraits of composer/performer and bird. In applying granular synthesis techniques to video, tiny units of image and sampled sound are reassembled within the frames. Through the mixing of existing synthesised sequences, performer/composer and bird become active participants in the making and remaking of a shared environment, articulating the limits of space/territory to find new ways to be heard within it. 